\title{
Öğretmen Adaylarının Çevreye Yönelik Ekosentrik, Antroposentrik ve Antipatik Tutumları
}

\section{Ecocentric, Antropocentric and Antipathetic Attitudes of Teacher Candidates towards the Environment}

\section{Hafife BOZDEMiR ${ }^{* \star}$}

\section{Melike FAiZ ${ }^{* \star \star}$}

Öz. Araştırmada, öğretmen adaylarının çevreye yönelik antroposentrik, ekosentrik ve antipatik tutumlarını belirlemek, bazı değişkenler açısından incelemek ve boyutlar arasındaki ilişkiyi tespit etmek amaçlanmıştır. Çalışmada ilişkisel tarama yöntem kullanıımıştır. 800 öğretmen adayı ile yürütülen araştırmanın verileri Erten (2007) tarafından Türkçe'ye uyarlanan Ekosentrik, Antroposentrik ve Çevreye Yönelik Antipatik Tutum Ölçeği ile toplanmıştır. Verilerin analizinde betimsel istatistikler, bağımsız gruplar $\mathrm{t}$ testi, tek yönlü varyans analizi kullanılmıştır. Illişkinin belirlenmesi için de Pearson Momentler Çarpımı Korelasyon Katsayısı hesaplanmışır. Verilerin analizi sonucunda ekosentrik tutumların kız öğrenciler, antipatik tutum puanlarının erkek öğrenciler lehine olduğu görülmüştür. Sınıf düzeyi değişkeni açısından düzey arttıkça ekosentrik tutum puanlarının arttığı ve antipatik tutum puanlarının azaldığı tespit edilmiştir. Öğrenim görülen lisans programı değişkeni bakımından öğretmen adaylarının antipatik tutum puanlarında Sosyal Bilgiler Eğitiminde öğrenim gören öğretmen adayları lehine anlamlı bir farklılık bulunmuştur. Ayrıca ekosentrik tutumla antroposentrik tutum arasında pozitif yönde; antipatik tutum arasında negatif yönde, antroposentrik ve antipatik tutumlar arasında da pozitif yönde anlamlı bir ilişki saptanmıştır. Bu doğrultuda eğitim fakültelerinde çevre merkezli yaklaşımları temel alan çevre eğitimi verilmesi önerilebilir.
\end{abstract}

Anahtar Kelimeler: Ekosentrik, antroposentrik, antipatik tutum, öğretmen adayları.

Abstract. In the study, determining the prospective teachers' anthropocentric, ecocentric and antipathetic attitudes towards environment, analyzing these in terms of some certain valuables and establishing the relationship among dimensions have been aimed at Comparative survey method has been used in the study. Data of the research carried out with the participation of 800 prospective teachers have been gathered by means of the Ecocentric, Anthropocentric and Antipathetic Environmental Attitude Scale, which was first adapted to Turkish by Erten (2007). In the analysis of data, descriptive statistics, independent groups $t$ test, one-way variance analysis have been used. Pearson Product Moment Correlation Coefficient has also been used in order that the relationship can be determined. As based on the research result, it has been seen that ecocentric attitudes are in favor of female students and antipathetic attitude points result in male students' favor. Considering the class level, it has been determined that ecocentric attitude points increase and antipathetic attitude points decrease, while the class level increases. With regards to the academic program studied at, a significant difference in favor of the prospective teachers receiving education in Social Studies Education has been found in the prospective teachers' antipathetic attitude points. Also, a significant relationship between ecocentric attitude and anthropocentric attitude has been detected as positively; between ecocentric attitude and antipathetic attitude as negatively; and also, between anthropocentric attitude and antipathetic attitude in a positive way. In this respect, ecocentric approaches based environmental education can be recommended in education faculties.

Keywords: Ecocentric, anthropocentric, antipathetic attitude, prospective teachers.

\section{Toplumsal Mesaj.}

Araştırmanın amacl, öğretmen adaylarının çevreye yönelik antroposentrik, ekosentrik ve antipatik tutumlarını belirlemek ve boyutlar arasındaki ilişkiyi bulmaktır. Ekosentrik tutumlarda kız öğrencilerin, antipatik tutumlarda erkek öğrencilerin puanları yüksektir. Sınıf düzeyi arttıkça ekosentrik tutum puanlarının arttığı ve antipatik tutum puanlarının azaldığı bulunmuştur. Antipatik tutum puanlarında, Sosyal Bilgiler Eğitimi öğretmen adaylarının puanları yüksektir.

\section{Public Interest Statement.}

The aim of the research is to determine the anthropocentric ecocentric and antipictive attitudes of the prospective teachers towards the environment and to find the relation between the dimensions. Female students in ecocentric attitudes and male students in antipathetic attitudes have higher scores. As the class level increased, ecocentric attitude scores increased and antipatik attitude scores decreased. In antipatched attitudes scores, Social Studies Education teacher candidates score higher.

\footnotetext{
* Bu makalenin bir bölümü Multidisciplinary Academic Conference on Education, Teaching and E-learning konferansında sözlü bildiri olarak sunulmuştur. 7-8 Ağustos 2015, Prag/Çek Cumhuriyeti.

** Yrd. Doç. Dr., Kastamonu Üniversitesi Eğitim Fakültesi, Temel Eğitim Anabilim Dalı, hbozdemir@kastamonu.edu.tr

${ }^{* * *}$ Yrd. Doç. Dr., Kastamonu Üniversitesi Eğitim Fakültesi, Türkçe ve Sosyal Bilimler Eğitimi Anabilim Dalı, mfaiz@kastamonu.edu.tr
} 


\section{GiRiş}

Günümüzde artan çevre sorunları ile birlikte çevre konusunda bilinçli, duyarlı bireyler yetiştirmek, sorunları önlemede ve bunlarla mücadele etmede etkili bir yol olarak görülmektedir (Uzun ve Sağlam, 2006). Çevre bilincine sahip bu bireyleri yetiştirmede çevre eğitimi gündeme gelmektedir. Çevre eğitimi, bireylerin çevreye yönelik bilgileri edinmesini sağlamakla birlikte olumlu tutumlarının gelişmesine ve bu tutumların davranışa dönüşmesine de yol açmaktadır (Erten, 2004). Çevre eğitiminde amaç, çevre ve çevre sorunları hakkında bilgi sahibi olan, bu sorunlarla başa çıkabilecek çözümler üretebilen ve bu çözümleri çevreci davranışlara dönüştüren, düşünen, tartışan, sorgulayan, sürdürülebilir yaşam ve sürdürülebilir kalkınmayı kavramış ve benimsemiş, dünya ile uyumlu bireyler yetiştirmektir (Atasoy ve Ertürk, 2008; Fisman, 2005; Pooley ve O'Connor, 2000). Öğrencilerin bilgi düzeylerini, algılarını, tutumlarını belirlemek ve bu konuda anlayış sahibi olmak etkili bir çevre eğitiminde önemli role sahiptir (Cardeiro ve Sayler, 1994). Bu bağlamda araştırmacılar genel olarak çevre sorunları ve bunun yanında ozon tabakasının incelmesi, küresel ısınma, sera etkisi, asit yağmurları gibi çevresel konularda farklı örneklem gruplarının anlayışlarını araştırmışlardır (Bahar, Bağ ve Bozkurt, 2008; Michail, Stamou ve Stamou, 2007; Ratinen, 2013). Aynı zamanda katılımcıların çevre ve çevre sorunlarına ilişkin algılarına yönelik araştırmalar da mevcuttur (Ateş ve Karatepe, 2013; Aydın, 2011; Seçgin, Yalvaç ve Çetin, 2010). Çevre eğitimi, çevreye yönelik olumlu tutumlar, çevreye karşı sorumlu davranışlar ve çevre bilinci konu/kavramları da araştırmacıların çalışma alanlarındandır (Demir ve Yoldaş, 2016; Eagles ve Demare, 1999; Erol ve Gezer, 2006; Esa, 2010; Pooley ve O'Connor, 2000; Sungur, 2017; Şama, 2003; Taylor, Doff, Jenkins ve Kennelly, 2007; Tuncer, Sungur, Tekkaya ve Ertepınar, 2007; Vlaardingbroek ve Taylor, 2007).

Yukarıda bahsedilen araştırmalarda da incelenen bu çevresel tutum ve davranışları etkileyen unsurlardan biri de çevre etiğidir (Gerçek, 2016). Çevre etiğine ilişkin literatürde farklı yaklaşımlar bulunmaktadır. Kortenkamp ve Moore (2001) çevreye ilişkin çıkmazları ahlaki sorgulama açısından değerlendirmiş, insan ve doğa arasındaki ilişkiyi içerecek şekilde ahlakın genişletilmesi düşüncesi temelinde çevre etiğini ifade etmiştir. Buradan hareketle antropesentrizm ve ekosentrizmi doğaya ilişkin etik anlayışlarda iki farklı yol olarak belirtmiştir.

Antroposentrizm, insanın tek başına gerçek değere sahip olduğunu kabul eden, insan merkezli bir yaklaşımdır. Insan merkezli bu perspektife göre, insanoğlunun çıkarları desteklenmektedir. Örneğin, hayvanlar, insanların çıkarlarını teşvik ettikleri ya da tıbbi, beslenme, koruma, duygusal, estetik vb. alanlarda yararlı oldukları sürece değerlidir anlayışı bu bakış açısını yansıtmaktadır. Ayrıca bu yaklaşım çevre veya doğanın kendi başına bir değeri olmadığını savunmakta ve çevrenin değerini insanı nasıl etkilediğine (MacKinnon ve Fiala, 2014) ve insanlara sağlayabileceği imkânlara göre değerlendirmektedir (Thompson ve Barton, 1994). Antroposentrik kişiler, insanların yaşamının devamı, bu sürecin niteliği için çevrenin korunması gerektiğine inanırlar ve insanlığa yararını göz önünde bulundururlar. Bu kişilerde çevresel sorunlar, insan sağlığına yönelik bir tehdit oluşturabileceği için önlenmeli; enerji ihtiyacımızın karşılanmasında doğal kaynakların önemli yeri olduğu için tutumlu kullanılmalı düşüncesi hâkimdir. Bu durumda antroposentrik tutumlar faydacı felsefeye dayanmaktadır (Erten, 2007).

Ekosentrik anlayışta, insana yararlılık merkezde değildir. Çevre, tüm canlı ve cansız unsurlarla birlikte bir değer taşımaktadır (Kortenkamp ve Moore, 2001; Thompson ve Barton, 1994). Doğa ve tabiat varlıklarının özündeki bu değerden dolayı ekosentristler, doğaya hayranlık ve saygı duyarak önem vermek gerektiğini savunmaktadır (MacKinnon ve Fiala, 2014). Örneğin ekosentrik kişiler yağmur ormanlarının kesilmemesi gerektiğini, çünkü aksi takdirde bitki ve hayvan türlerinin yok olabileceği düşüncesindedirler (Kortenkamp ve Moore, 2001).

Açıklanan antroposentrik ve ekosentrik yaklaşımların yanında antipatik tutumlar da bulunmaktadır. Bu tutumların, artan çevre koruma hareketlerine karşı bir tepki olarak ortaya çıkabileceği düşünülmektedir (Atlı vd., 2015). Thompson ve Barton (1994) tarafından geliştirilen ölçeğin de bir boyutunda antipatik tutumlar yer almaktadır. Bu anlayışlara yönelik literatür incelendiğinde farklı öğretim kademesindeki öğrenciler, öğretmen adayları ve halk üzerinde çalışmalar yapıldığı 
görülmektedir (Atlı vd., 2015; Casey ve Scott, 2006; Erten ve Aydoğdu, 2011; Karakaya ve Çobanoğlu, 2012; Özdemir, 2014; Sürmeli ve Saka, 2013). Bu araştırmalarda çevreye yönelik antroposentrik, ekosentrik ve antipatik tutumlar, cinsiyet, öğrenim görülen program vb. demografik değişkenler açısından incelenmiştir. Öğretmen adaylarıyla yapılan araştırmalar incelendiğinde Karakaya ve Çobanoğlu'nun çalışmasında (2012) cinsiyet değişkeninde kız öğrenciler, öğrenim görülen programdaysa okul öncesi öğretmenliği lehine anlamlı bir farklıık bulunmuştur. Bunun yanında Sürmeli ve Saka'nın (2013) araştırmasında bu iki değişken açısından öğrenciler arasında anlamlı bir farklılığın olmadığı tespit edilmiştir.

Erten ve Aydoğdu (2011) bireylerin çevre bilincini ve çevreyi korumasındaki davranışlarını yukarıdaki araştırmaların da odak noktasını oluşturan anlayışların belirlediğini ifade etmektedir. Bu açıdan araştırmada, çevre eğitiminde, çevre bilincini kazandırmada önemli rolü olacă̆ı düşünülen geleceğin öğretmenlerinin çevreye yönelik antroposentrik, ekosentrik ve antipatik tutumları ve anlayışları tespit edilmek istenmiştir.

\subsection{Problem}

Mevcut çalışmanın gerçekleştiridiği eğitim fakültesinde çevre odaklı derslerin daha fazla bulunduğu lisans programları Sınıf Eğitimi, Sosyal Bilgiler Eğitimi ve Fen Bilgisi Eğitimi'dir. Çevre konuları özellikle Sınıf Eğitimi'nde Genel Biyoloji, Genel Coğrafya, Türkiye Coğrafyası ve Jeopolitiği, Çevre Eğitimi derslerinde; Sosyal Bilgiler Eğitimi'nde Genel Fiziki Coğrafya, Türkiye Fiziki Coğrafyası, Genel Beşeri ve Ekonomik Coğrafya, Türkiye Beşeri ve Ekonomik Coğrafyası, Ülkeler Coğrafyası, Siyasi Coğrafya, Günümüz Dünya Sorunları derslerinde; Fen Bilgisi Eğitimi'nde Genel Biyoloji I, II, Genetik ve Biyoteknoloji, Çevre Bilimi, Yer Bilimi, Biyolojide Özel Konular derslerinde yer almaktadır.

Araştırmada da eğitim fakültesi lisans programında çevre odaklı derslerin daha fazla olduğu Sınıf Eğitimi, Sosyal Bilgiler Eğitimi ve Fen Bilgisi Eğitimi programlarında öğrenim gören öğretmen adaylarının çevreye yönelik antroposentrik, ekosentrik ve antipatik tutumlarını belirlemek ve aralarındaki ilişkiyi tespit etmek amaçlanmıştır. Bu amaç doğrultusunda aşağıdaki sorulara cevap aranmıştır.

1. Öğretmen adaylarının çevreye yönelik antroposentrik, ekosentrik ve antipatik tutumları cinsiyete göre farklılaşmakta mıdır?

2. Öğretmen adaylarının çevreye yönelik antroposentrik, ekosentrik ve antipatik tutumları sınıf düzeyine göre farklılaşmakta mıdır?

3. Öğretmen adaylarının çevreye yönelik antroposentrik, ekosentrik ve antipatik tutumları öğrenim görülen programa göre farklılaşmakta mıdır?

4. Öğretmen adaylarının çevreye yönelik antroposentrik, ekosentrik ve antipatik tutumları arasında bir ilişki var mıdır?

\section{YÖNTEM}

Sınıf Eğitimi, Sosyal Bilgiler Eğitimi ve Fen Bilgisi Eğitimi lisans programlarında öğrenim gören öğretmen adaylarının çevreye ilişkin antroposentrik, ekosentrik ve antipatik tutumlarını belirlemeyi, cinsiyet, sınıf düzeyi, öğrenim görülen program değişkenleri açısından incelemeyi ve aralarındaki ilişkiyi tespit etmeyi amaçlayan araştırmada ilişkisel tarama yöntemi kullanılmıştır. Bu tür araştırmalarda iki veya daha fazla değişken arasındaki ilişkiler incelenir ve mevcut ilişki açıklanır (Fraenkel ve Wallen, 2009).

\section{1 Çalışma Grubu}

Araştırmanın çalışma grubunu Kastamonu Üniversitesi Eğitim Fakültesi Sınıf Eğitimi, Sosyal Bilgiler Eğitimi ve Fen Bilgisi Eğitimi lisans programlarında öğrenim gören 800 öğretmen adayı oluşturmaktadır. Öğretmen adaylarının bu programlardan seçilmesinin nedeni çevre konulu derslerin bu bölümlerde daha çok yer almasından kaynaklanmaktadır. Öğretmen adaylarına ilişkin bilgiler Tablo 1'de yer almaktadır. 
Tablo 1. Çalışma Grubundaki Öğretmen Adaylarının Özellikleri

\begin{tabular}{|c|c|c|c|c|c|c|c|}
\hline & & & \multicolumn{4}{|c|}{ Sınıf düzeyi } & \multirow[b]{2}{*}{ Toplam } \\
\hline & & & 1. sinıf & 2. sinıf & 3. sinıf & 4. sinıf & \\
\hline & Cinsiyet & $\mathrm{KIZ}$ & 28 & 77 & 49 & 73 & 227 \\
\hline \multirow[t]{3}{*}{ Sinıf } & & Erkek & 7 & 24 & 13 & 37 & 81 \\
\hline & & Toplam & 35 & 101 & 62 & 110 & 308 \\
\hline & Cinsiyet & $\mathrm{KIZ}$ & 31 & 38 & 29 & 49 & 147 \\
\hline \multirow[t]{3}{*}{ Sosyal } & & Erkek & 29 & 33 & 26 & 39 & 127 \\
\hline & & Toplam & 60 & 71 & 55 & 88 & 274 \\
\hline & Cinsiyet & $\mathrm{KIZ}$ & 39 & 34 & 51 & 46 & 170 \\
\hline \multirow[t]{3}{*}{ Fen } & & Erkek & 3 & 14 & 21 & 10 & 48 \\
\hline & & Toplam & 42 & 48 & 72 & 56 & 218 \\
\hline & Cinsiyet & $\mathrm{KIZ}$ & 98 & 149 & 129 & 168 & 544 \\
\hline \multirow[t]{2}{*}{ Toplam } & & Erkek & 39 & 71 & 60 & 86 & 256 \\
\hline & & Toplam & 137 & 220 & 189 & 254 & 800 \\
\hline
\end{tabular}

\subsection{Veri Toplama Aracı}

Araştırmada veriler Thompson ve Barton (1994) tarafından geliştirilen Erten (2007) tarafından Türkçe'ye uyarlanan Ekosentrik, Antroposentrik ve Çevreye Yönelik Antipatik Tutum Ölçeği kullanılarak toplanmıştır. Ekosentrik tutumlarda 12, antroposentrik tutumlarda 8 ve antipatik tutumlarda 7 madde olmak üzere ölçekte 27 madde bulunmaktadır. Ölçek, likert tipi ve 7'li dereceleme ölçeğinde geliştirilmiştir. Ölçekteki maddeler hiç katılmıyorum, katılmıyorum, çok az katılmıyorum, kararsızım, biraz katılıyorum, katılıyorum, tamamen katılıyorum, şeklinde 1'den 7'ye kadar derecelendirilmiştir. Ölçekte yer alan boyutlardan alınabilecek en düşük, orta ve en yüksek tutum puanları incelendiğinde, ekosentrik tutum boyutunda en düşük puan $12(12 \times 1)$, orta puan 42 $(12 \times 3,5)$ ve en yüksek puan $84(12 \times 7)$; antroposentrik tutum boyutunda en düşük puan $8(8 \times 1)$, orta puan $28(8 \times 3,5)$ ve en yüksek puan $56(8 \times 7)$; antipatik tutum boyutunda en düşük puan 7 (7x1), orta puan $24,5(7 \times 3,5)$ ve en yüksek puan 49 (7x7) olarak hesaplanmaktadır. Uyarlanan ölçekte ekosentrik tutumların Cronbach Alpha güvenirlik katsayısı .77; antroposentrik tutumların Cronbach Alpha güvenirlik katsayısı .78; antipatik tutumların Cronbach Alpha güvenirlik katsayısı .92 olarak hesaplanmıştır. Bu çalışmada ekosentrik tutumların Cronbach Alpha güvenirlik katsayısı .77; antroposentrik tutumların Cronbach Alpha güvenirlik katsayısı .70; antipatik tutumların Cronbach Alpha güvenirlik katsayısı .87 olarak bulunmuştur.

\subsection{Verilerin Analizi}

Araştırmada toplanan veriler SPSS 21 Programı kullanılarak analiz edilmiştir. Araştırmada çalışma grubunda yer alan öğrencilerin antroposentrik, ekosentrik ve antipatik tutum puanları için betimsel istatistikler, bu puanlar arasında cinsiyete göre istatistiksel olarak anlamlı bir fark olup olmadığı konusunda bağımsız gruplar $t$ testi yapılmıştır. Sınıf düzeyi ve öğrenim görülen program değişkenleri açısından tek yönlü varyans analizi (ANOVA) kullanılmıştır. Ölçekteki antroposentrik, ekosentrik ve antipatik tutum puanları arasındaki ilişkinin tespit edilmesi için Pearson Momentler Çarpımı Korelasyon katsayısı hesaplanmıştır.

\section{BULGULAR}

Bu bölümde, öğretmen adaylarının ölçeğe verdikleri yanıtlar doğrultusunda çevre merkezli (ekosentrik), antroposentrik ve antipatik tutumlarına yönelik elde edilen bulgulara yer verilmiştir. Bu doğrultuda öğretmen adaylarının ölçeğe verdikleri yanıtlar incelenmiş, cinsiyet, sınıf ve öğrenim 
görülen program değişkenleri yönüyle değerlendirme yapılmıştır. Buna ek olarak ölçekte yer alan boyutlar arasındaki ilişkiler tablolar halinde aşağıda sunulmuştur.

Öğretmen adaylarının ölçekten aldıkları çevre merkezli, antroposentrik ve antipatik tutum puanlarına yönelik betimsel istatistiklere Tablo 2'de yer verilmiştir.

Tablo 2. Öğretmen Adaylarının Çevreye Yönelik Ekosentrik, Antroposentrik ve Antipatik Tutumlarına İlişkin Betimsel İstatistikler

\begin{tabular}{lccccc}
\hline Boyutlar & $\mathrm{n}$ & En Düşük & En Yüksek & $\overline{\mathrm{X}}$ & ss \\
\hline $\begin{array}{l}\text { Ekosentrik Tutum (12 } \\
\text { madde) }\end{array}$ & 800 & 12 & 84 & 70.35 & 7.86 \\
$\begin{array}{l}\text { Antroposentrik Tutum (8 } \\
\text { madde) }\end{array}$ & 800 & 8 & 56 & 44.39 & 6.56 \\
$\begin{array}{l}\text { Antipatik Tutum (7 madde) } \\
\text { (12 }\end{array}$ & 800 & 7 & 49 & 19.07 & 9.58 \\
\hline
\end{tabular}

Tablo 2'ye göre, öğretmen adaylarının ekosentrik tutum puanları ile antroposentrik tutum puanlarının orta puanın üstünde; diğer boyut olan antipatik tutum puanlarının orta puanın altında olduğu bulunmuştur. Öğretmen adaylarının çevreye yönelik ekosentrik, antroposentrik ve antipatik tutumlarını yansıtan bu puanların cinsiyet değişkeni açısından farklılaşma durumu incelenmiş ve bunun için yapılan bağımsız t-testi analizi sonucunda elde edilen bulgular Tablo 3'te sunulmuştur.

Tablo 3. Öğretmen Adaylarının Ekosentrik, Antroposentrik ve Antipatik Tutumlarının Cinsiyete Göre Bağımsız t-Testi Analiz Sonuçları

\begin{tabular}{llllllll}
\hline Tutumlar & Cinsiyet & $\mathrm{n}$ & $\overline{\mathrm{X}}$ & $\mathrm{ss}$ & $\mathrm{sd}$ & $\mathrm{t}$ & $\mathrm{p}$ \\
\hline \multirow{2}{*}{ Ekosentrik } & $\mathrm{K}$ Kz & 544 & 71.13 & 7.27 & 798 & 4.099 & $.000^{*}$ \\
& Erkek & 256 & 68.71 & 8.76 & & & \\
\hline \multirow{2}{*}{ Antroposentrik } & $\mathrm{K}$ Iz & 544 & 44.66 & 6.54 & 798 & 1.69 & .091 \\
& Erkek & 256 & 43.82 & 6.59 & & & \\
\hline \multirow{2}{*}{ Antipatik } & KIz & 544 & 18.23 & 9.05 & 798 & -3.629 & $.000^{*}$ \\
& Erkek & 256 & 20.85 & 10.42 & & & \\
\hline * $<.05$ & & & & & & &
\end{tabular}

Tablo 3 incelendiğinde öğretmen adaylarının ekosentrik ve antipatik tutum puan ortalamalarının cinsiyete göre farklılaştığı görülmektedir $\left[\mathrm{t}_{(798)}=4.099, \mathrm{p}<0.05 ; \mathrm{t}_{(798)}=-3.629, \mathrm{p}<0.05\right]$. Antroposentrik tutum puanları arasında istatistiki olarak anlamlı bir farklılık tespit edilmemiştir $\left[\mathrm{t}_{(798)}=1.69, \mathrm{p}>0.05\right]$. Ekosentrik tutum puanları açısından kız öğrenciler ( $\overline{\mathrm{X}}=71.13)$, erkek öğrencilerden $(\overline{\mathrm{X}}=68.71)$ daha yüksek puan ortalamasına sahiptir. Antipatik tutum puanlarında ise kız öğrencilerin puanları $(\bar{X}=18.23)$ erkek öğrencilere ( $\bar{X}=20.85)$ oranla daha düşük bulunmuştur.

Araştırmada diğer bir değişken sınıf düzeyidir. Sınıf düzeyine yönelik olarak öğrencilerin ekosentrik, antroposentrik ve antipatik tutum puanlarına ilişkin bulgular Tablo 4'te yer almaktadır. 
Tablo 4. Öğretmen Adaylarının Ekosentrik, Antroposentrik ve Antipatik Tutumlarının Sınıf Düzeyine Göre Betimsel İstatistikleri

\begin{tabular}{lllll}
\hline & Sınıf Düzeyi & $\mathrm{n}$ & $\overline{\mathrm{X}}$ & ss \\
\hline \multirow{3}{*}{ 1. Sınıf } & 137 & 69.36 & 8.67 \\
2. Sınıf & 220 & 69.43 & 8.38 \\
& 3. Sınıf & 189 & 70.64 & 7.64 \\
& 4. Sınıf & 254 & 71.48 & 6.91 \\
& Toplam & 800 & 70.35 & 7.86 \\
\hline \multirow{3}{*}{ Antroposentrik } & 1. Sınıf & 137 & 45.02 & 7.05 \\
& 2. Sınıf & 220 & 45.18 & 6.06 \\
& 3. Sınıf & 189 & 43.78 & 6.29 \\
& 4. Sınıf & 254 & 43.80 & 6.84 \\
& Toplam & 800 & 44.39 & 6.56 \\
\hline 1. Sınıf & 137 & 20.69 & 10.62 \\
2. Sınıf & 220 & 20.67 & 10.14 \\
3. Sınıf & 189 & 18.77 & 9.47 \\
4. Sınıf & 254 & 17.02 & 8.10 \\
& Toplam & 800 & 19.07 & 9.58 \\
\hline
\end{tabular}

Tablo 4 incelendiğinde öğretmen adaylarının ekosentrik tutum puanlarında en yüksek puanın $(\overline{\mathrm{X}}=71.48) 4$. sınıflara ait olduğu bulunmuştur. Buna ek olarak antroposentrik tutum puanlarında 1 ve 2. sınıfların puanlarının birbirine çok yakın olduğu ve en yüksek ortalamanın ( $\bar{X}=45.18) 2$. sınıflarda olduğu görülmektedir. Antipatik tutum puanlarında da benzer şekilde 1 ve 2 . sınıfların puanları birbirine çok yakın ve en yüksek puan $(\bar{X}=20.69)$ 1. sınıf düzeyindedir. Öğrencilerin aldıkları bu puanların sınıf düzeyi değişkeni açısından farklılaşma durumunun incelenmesi için tek yönlü varyans analizi yapıımıştır. Analiz sonuçları Tablo 5'te sunulmuştur.

Tablo 5. Öğretmen Adaylarının Ekosentrik, Antroposentrik ve Antipatik Tutumlarının Sınıf Düzeyine Göre Tek Yönlü Varyans Analizi Sonuçları

\begin{tabular}{lllllll}
\hline Boyutlar & $\begin{array}{l}\text { Varyansın } \\
\text { Kaynağı }\end{array}$ & $\begin{array}{l}\text { Kareler } \\
\text { Toplamı }\end{array}$ & sd & $\begin{array}{l}\text { Kareler } \\
\text { Ortalaması }\end{array}$ & $F$ & $p$ \\
\hline \multirow{2}{*}{ Ekosentrik } & Gruplar Arası & 664.30 & 3 & 221.44 & 3.623 & $.013^{*}$ \\
& Goçi & 48652.97 & 796 & 61.12 & & \\
& Toplam & 49317.28 & 799 & & & \\
\hline
\end{tabular}




\begin{tabular}{lllllll}
\hline & Gruplar Arası & 351.54 & 3 & 117.18 & 2.737 & $.043^{*}$ \\
Antroposentik & Grup İçi & 34079.76 & 796 & 42.81 & & \\
& Toplam & 34431.30 & 799 & & & \\
\hline \multirow{2}{*}{ Antipatik } & Gruplar Arası & 2005.25 & 3 & 668.42 & 7.455 & $.000 *$ \\
& Grup İçi & 71368.91 & 796 & 89.66 & & \\
& Toplam & 73374.16 & 799 & & & \\
\hline p $<.05$ & & & & & &
\end{tabular}

Tablo 5'e göre öğretmen adaylarının ekosentrik, antroposentrik ve antipatik tutum puanları arasında sınıf düzeyine göre anlamlı bir farklılık bulunmuştur ( $F=3.623, p<.05 ; F=2.737, p<.05$; $F=7.455, p<.05)$.

Öğretmen adaylarının sınıf düzeyi değişkeni açısından ekosentrik, antroposentrik ve antipatik tutum puanlarının Tukey testi karşılaştırması yapılarak analiz sonuçları Tablo 6'da sunulmuştur.

Tablo 6. Öğretmen Adaylarının Ekosentrik, Antroposentrik ve Antipatik Tutumlarının Sınıf Düzeyi Değişkenine ilişkin Tukey Testi Analiz Sonuçları

\begin{tabular}{lccccc}
\hline Boyutlar & \multicolumn{2}{c}{ Sınıf düzeyi } & Ortalamalar farkı & Standart hata & $p$ \\
\hline Ekosentrik & 4. sınıf & 2. sınıf & $2.06^{*}$ & .72 & .023 \\
\hline \multirow{2}{*}{ Antipatik } & 1. sınıf & 4. sınıf & $3.67^{*}$ & 1.00 & .002 \\
& 2. sınıf & 4. sınıf & $3.65^{*}$ & .87 & .000 \\
\hline
\end{tabular}

Tablo 6'ya göre ekosentrik tutum puanları açısından 2. ve 4. sınıf düzeyindeki öğrencilerin puanları karşılaştırıldığında 4. sınıf öğrencileri lehine anlamlı bir fark tespit edilmiştir. Antipatik tutum puanlarına yönelik 1. ve 4. sınıf; 2 . ve 4. sınıf düzeyindeki öğrencilerin puanları karşılaştıııldığında ise sırasıyla 1. ve 2. sınıf öğrencileri lehine anlamlı fark çıkmıştır.

Araştırmada öğrenim görülen program açısından öğretmen adaylarının ekosentrik, antroposentrik ve antipatik tutum puanları da incelenmiştir. Öğrenim görülen programa yönelik olarak öğrencilerin ekosentrik, antroposentrik ve antipatik tutum puanlarına ilişkin bulgular Tablo 7'de sunulmuştur.

Tablo 7. Öğretmen Adaylarının Ekosentrik, Antroposentrik ve Antipatik Tutumlarının Öğrenim Görülen Programa Göre Betimsel Istatistikleri

\begin{tabular}{llccc}
\hline Boyutlar & Program & $\mathrm{n}$ & $\overline{\mathrm{X}}$ & ss \\
\hline \multirow{3}{*}{ Ekosentrik } & Sınıf Eğitimi & 308 & 70.58 & 7.46 \\
& Sosyal Bilgiler Eğitimi & 274 & 70.14 & 8.48 \\
& Fen Bilgisi Eğitimi & 218 & 70.31 & 7.61 \\
& Toplam & 800 & 70.35 & 7.86 \\
\hline
\end{tabular}




\begin{tabular}{lllll}
\hline & Sınıf Ĕ̆itimi & 308 & 44.19 & 6.56 \\
\multirow{2}{*}{ Antroposentrik } & Sosyal Bilgiler Eğitimi & 274 & 44.96 & 6.35 \\
& Fen Bilgisi Eğitimi & 218 & 43.94 & 6.82 \\
& Toplam & 800 & 44.39 & 6.56 \\
\hline \multirow{3}{*}{ Antipatik } & Sınıf Ĕgitimi & 308 & 18.21 & 8.65 \\
& Sosyal Bilgiler Eğitimi & 274 & 20.71 & 10.39 \\
& Fen Bilgisi Eğitimi & 218 & 18.21 & 9.56 \\
& Toplam & 800 & 19.07 & 9.58
\end{tabular}

Tablo 7'ye göre öğretmen adaylarının ekosentrik tutum puanlarında en yüksek puanın ( $\overline{\mathrm{X}}=70.58)$ Sınıf Eğitimi öğrencilerine ait olduğu görülmüştür. Bunun yanında antroposentrik ve antipatik tutum puanlarında en yüksek ortalamaya (sırasıyla $\overline{\mathrm{X}}=44.96$; $\overline{\mathrm{X}}=20.71$ ) Sosyal Bilgiler Eğitimi öğrencilerinin sahip olduğu saptanmıştır. Öğretmen adaylarının bu tutum puanlarının öğrenim görülen programa yönelik farklılaşma durumunun incelenmesi için tek yönlü varyans analizi yapılmıştır. Analiz sonuçları Tablo 8'de sunulmuştur.

Tablo 8. Öğretmen Adaylarının Ekosentrik, Antroposentrik ve Antipatik Tutumlarının Öğrenim Görülen Programa Göre Tek Yönlü Varyans Analizi Sonuçları

\begin{tabular}{|c|c|c|c|c|c|c|}
\hline Boyutlar & $\begin{array}{l}\text { Varyansın } \\
\text { Kaynağı }\end{array}$ & $\begin{array}{l}\text { Kareler } \\
\text { Toplamı }\end{array}$ & sd & $\begin{array}{c}\text { Kareler } \\
\text { Ortalaması }\end{array}$ & $\mathrm{F}$ & $\mathrm{p}$ \\
\hline & Gruplar Arası & 27.922 & 2 & 13.961 & .226 & .798 \\
\hline \multirow[t]{3}{*}{ Ekosentrik } & Grup İçi & 49289.354 & 797 & 61.844 & & \\
\hline & Toplam & 49317.276 & 799 & & & \\
\hline & Gruplar Arası & 146.112 & 2 & 73.056 & 1.698 & .184 \\
\hline \multirow[t]{3}{*}{ Antroposentik } & Grup İçi & 34285.185 & 797 & 43.018 & & \\
\hline & Toplam & 34431.297 & 799 & & & \\
\hline & Gruplar Arası & 1126.602 & 2 & 563.301 & 6.214 & $.002 *$ \\
\hline \multirow[t]{2}{*}{ Antipatik } & Grup İçi & 72247.559 & 797 & 90.649 & & \\
\hline & Toplam & 73374.160 & 799 & & & \\
\hline
\end{tabular}

$* \overline{\mathrm{p}<.05}$

Tablo 8 incelendiğinde öğretmen adaylarının ekosentrik, antroposentrik tutum puanlarında öğrenim görülen programa göre anlamlı bir fark bulunmazken antipatik tutum puanları arasında anlamlı bir farklılık bulunmuştur $(\mathrm{F}=6.214, \mathrm{p}<.05)$.

Öğretmen adaylarının öğrenim görülen program değişkeni açısından antipatik tutum puanları Tukey testi karşılaştırması yapılarak analiznsonuçları Tablo 9'da yer verilmiştir. 
Tablo 9. Öğretmen Adaylarının Antipatik Tutum Puanlarının Öğrenim Görülen Programa İlişkin Tukey Testi Analiz Sonuçları

\begin{tabular}{lllll}
\hline Boyutlar & Sınıf düzeyi & $\begin{array}{l}\text { Ortalamalar } \\
\text { farkı }\end{array}$ & Standart hata & $p$ \\
\hline Antipatik Sosyal & Sınıf & $2.50 *$ & .79 & .005 \\
& Fen & $2.50 *$ & .86 & .011
\end{tabular}

Tablo 9'a göre antipatik tutum puanları açısından Sosyal Bilgiler Eğitimi öğrencileri ile Sınıf Eğitimi ve Fen Bilgisi Ĕgitimi öğrencileri karşılaştırıldığında Sosyal Bilgiler Eğitimi öğrencileri lehine anlamlı bir fark tespit edilmiştir.

Çalışma kapsamında öğretmen adaylarının ekosentrik, antroposentrik ve antipatik tutum puanları arasındaki ilişki de incelenmiş olup buna ilişkin sonuçlar Tablo 10'da verilmiştir.

Tablo 10. Değişkenlerin Aritmetik Ortalama, Standart Sapma ve Korelasyon Değerleri

\begin{tabular}{lccccc}
\hline Değişkenler & $\overline{\mathrm{X}}$ & ss & 1 & 2 & 3 \\
\hline 1.Ekosentrik tutum & 70.35 & 7.86 & 1 & $.275^{\star *}$ & $-.316^{\star *}$ \\
2.Antroposentrik tutum & 44.39 & 6.56 & & 1 & $.136^{\star *}$ \\
3.Antipatik tutum & 19.07 & 9.58 & & & 1 \\
\hline
\end{tabular}

Tablo 10'da yer alan boyutlara yönelik ilişki incelendiğinde ekosentrik tutum puanları ile antroposentrik tutum puanları arasında düşük düzeyde pozitif yönde bir ilişki vardır $(r=.275$, $\mathrm{p}<.01)$. Benzer şekilde antroposentrik tutum puanları ile antipatik tutum puanları arasında da düşük düzeyde pozitif yönde bir ilişki görülmektedir $(r=.136, p<.01)$. Ekosentrik tutum puanları ile antipatik tutum puanları arasındaki ilişkinin ise düşük düzeyde negatif yönde olduğu saptanmıştır $(r=.-316, p<.01)$.

\section{SONUÇ, TARTIŞMA VE ÖNERILER}

Bu çalışmada çevre odaklı derslerin daha fazla yer aldı̆̆ı lisans programlarında öğrenim görmekte olan öğretmen adaylarının ekosentrik, antroposentrik ve antipatik tutumlarını ortaya çıkarmayı ve bazı değişkenler açısından incelemek amaçlanmıştır. Araştırmanın sonucunda öğretmen adaylarının çevreye yönelik ekosentrik ve antroposentrik tutum puanlarının düzey olarak orta puanın üstünde ve antipatik tutum puanlarının ise altında olduğu ortaya çıkmıştır. Böylece öğretmen adaylarının çevreye yönelik tutumlarının daha çok çevre merkezli olduğu ancak insan odaklı bir çevre tutumunun da öğretmen adaylarında var olduğu görülmektedir. İnsanı merkeze alan bir anlayışta insana yararlılık önceliklidir. Doğa, insana katkı sağladığı ve intiyaçlarını karşıladığı sürece bir değer taşımaktadır. Bu yüzden doğa merkezli tutumları daha fazla olan kişilerin, doğaya tüm unsurlarla birlikte kendi değerini verdiğinden daha az insan merkezli tutum geliştirmesi beklenmektedir. Ancak, araştırmada öğretmen adaylarının insan merkezli tutumlarında bu durum görülmemektedir. Erten ve Aydoğdu (2011) tarafından da öğretmen adaylarının hem ekosentrik hem de antroposentrik tutumlarının fazla olduğu tespit edilmiştir. Her iki anlayışa yönelik tutumların fazla olması beklenen bir sonuç olmamasına rağmen öğretmen adaylarının çevreye yönelik olumlu tutumları bulunmaktadır. Katılımcıların çevrenin korunması konusunda daha az itici tutuma sahip olması da bunu destekler niteliktedir. Bu tutumlar ve aynı doğrultudaki davranışlar gerek günümüzde gerekse gelecekte doğanın korunmasına katkı sağlayacaktır. Öğretmen adaylarının da çevreye karşı itici tutumlarının düşük düzeyde olmasının gelecek nesillerin doğaya karşı olumlu tutum ve davranışlarını yönlendirmede önemli olduğu düşünülmektedir. 
Cinsiyete göre öğrencilerin ekosentrik tutumları incelendiğinde kız öğrencilerin erkek öğrencilere oranla daha fazla çevre merkezli tutuma sahip olduğu bulunmuştur. Karakaya ve Çobanoğlu'nun (2012) çalışmasında doğa merkezli bakış bakımından kız öğrenciler lehine bulunan anlamlı farklılık bu bulgu ile benzerlik taşımaktadır. Erten ve Aydoğdu'nun (2011) çalışmasında da aynı şekilde Türkiye'deki kız öğrencilerin ekosentrik tutumlarının daha fazla olduğu ortaya konmuştur. Buna karşın aynı çalışmada Azerbaycanlı öğrenciler açısından cinsiyet değişkenine yönelik bu tutum puanları bir farklılık göstermemiştir. Aynı şekilde Sürmeli ve Saka (2013) da araştırmalarında cinsiyet açısından öğretmen adaylarının tutum puanlarında istatistiksel olarak anlamlı bir farklılı̆ın olmadığını tespit etmiştir. Bunun yanında Uitto vd., (2011) 9. sınıf öğrencileri ile yürüttüğü çalışmalarında da tutumlar ve biyosentrik değerlere yönelik olarak kız öğrenciler lehine anlamlı bir fark bulmuştur. Casey ve Scott (2006) Avustralya halkı ile yaptıkları çalışmada cinsiyetin ekosentrik tutum açısından belirleyici olduğunu belirtmiş ve kadınların daha fazla çevre merkezli kaygı duyduğunu tespit etmiştir. Bu durumun kadınların geleneksel olarak merhametli, besleyici ve koruyucu toplumsal rollerinden kaynaklandığını belirtmiştir. Leppanen vd. (2012) de ebeveynler ve çocukları üzerinde yaptıkları araştırmada annelerin ve kızları arasında daha olumlu çevresel tutumlar saptamış ve cinsiyet rolleri hakkında düşüncelerin tutumları etkileyebileceğini ifade etmiştir. Öğretmen adaylarının antroposentik tutumlarında anlamlı bir fark bulunmamıştır. Ancak insanı doğanın en önemli parçası gören ve bu yüzden doğayı korumak gerektiğine inanan bir anlayış da öğretmen adaylarında mevcuttur. Öğretmen adaylarının bu tutumunun gelecekteki öğretmenlik hayatına ve öğrencilerine de yansıyabileceği düşünüldüğünde, çevre problemlerinin önlenmesinde, giderilmesinde, geliştirilecek tutum ve davranışlar konusunda sorun oluşturabilir. Aynı zamanda -insan için kullanımından kaynaklı olarak- çevreye yönelik olumsuz davranışların oluşturulmasına da zemin oluşturabilir. Antipatik tutumları incelendiğinde erkek öğrencilerin kız öğrencilere oranla daha fazla çevreye yönelik antipatik tutumlarının olduğu söylenebilir. Buradan hareketle çevre merkezli tutumları yüksek olan kız öğrencilerin antipatik tutumlarının daha düşük düzeyde olduğu görülmüştür. Doğa ve çevre odaklı bakış açısına sahip olan ve bu doğrultuda daha fazla olumlu tutuma sahip kız öğrencilerin, çevre konusunda antipatik tutumlarının düşük olması beklenen bir sonuçtur. Literatürde de araştırma sonucunu destekler nitelikte çalışmalar mevcuttur (Alpak Tunç, 2015; Erten ve Aydoğdu, 2011)

Mevcut araştırmada sınıf düzeyi açısından öğretmen adaylarının ekosentrik, antropesentrik ve antipatik tutumlarına yönelik sonuçlar da elde edilmiştir. Ekosentrik tutum puanları incelendiğinde 4. sınıf öğrencilerinin daha yüksek düzeyde tutuma sahip olduğu tespit edilmiştir. Sınıf düzeyi arttıkça tutum puanları da aynı yönde artmaktadır. Antipatik tutum puanları ise en düşük 4. sınıf düzeyindedir. Bu durum sınıf düzeyi arttıkça alınan derslerle ilişkilendirilebilir. Çünkü özellikle çevre konu/kavramların yer aldığı Çevre Eğitimi dersi Sınıf Eğitiminde 4. sınıf; Günümüz Dünya Sorunları dersi Sosyal Bilgiler Eğitiminde 4. sınıf; Çevre Bilimi dersi Fen Bilgisi Eğitiminde 3. sınıfta alınmaktadır. Bu durumun sınıf düzeyi arttıkça öğretmen adaylarının çevre merkezli tutumlarını olumlu yönde etkilemiş olabileceği ve aynı yönde itici tutumlarında da azalmaya yol açabileceği düşünülmektedir.

Öğrenim görülen program açısından öğretmen adaylarının ekosentrik ve antroposentik tutumlarında anlamlı bir farklılık saptanmamıştır. Sürmeli ve Saka'nın (2013) çalışması da bu araştırmanın sonuçlarını desteklemektedir. Antipatik tutumlarında ise anlamlı bir farklıık söz konusudur. Karakaya ve Çobanoğlu'nun (2012) araştırmasında öğrenim görülen programa göre Okul Öncesi Eğitimi öğrencileri, en düşük düzeyde insan merkezli çevre anlayışına sahiptir. Bu sonuç cinsiyete göre dağılım ile ilişkilendirilmiştir. Kız öğrenciler, doğa merkezli tutum daha fazla, itici tutum ise daha az göstermektedir (Alpak Tunç, 2015; Erten ve Aydoğdu, 2011; Karakaya ve Çobanoğlu, 2012; Uitto vd., 2011). Okul Öncesi Eğitiminde kız öğrenci sayısının fazla olmasından kaynaklı olarak bu lisans programında öğrenim gören öğrencilerin insan merkezli anlayıştan uzak olduğu belirtilmiştir. Mevcut çalışmada da benzer bir durum görülmektedir. Katılımcıların cinsiyete göre dağılımına bakıldığında erkek öğrenci sayısının en fazla olduğu lisans programı Sosyal Bilgiler Eğitimi'dir. Aynı şekilde araştırmada erkek öğrencilerin ekosentrik tutumları kız öğrencilere göre 
daha düşük düzeyde, antipatik tutumları daha yüksek düzeydedir. Bu yüzden Sosyal Bilgiler Eğitimi öğrencilerinin diğer lisans programlarına oranla daha fazla antipatik tutuma sahip olduğu düşünülmektedir. Ayrıca Sosyal Bilgiler Eğitimi programında çevre konu/kavramları özellikle Coğrafya derslerininin içeriklerinde yer almaktadır. Sınıf Eğitimi ve Fen Bilgisi Eğitiminde ise bu konu/kavramlara ilişkin belirli bir ders bulunmaktadır. Sınıf düzeyi değişkenine benzer şekilde, öğrenim görülen program açısından öğretmen adaylarının tutum puanlarındaki farklılaşmanın da alınan derslere bağı olarak değiştiği söylenebilir.

Çevreye yönelik ekosentrik, antroposentrik ve antipatik tutumlar arasında ilişki incelendiğinde öğretmen adaylarının ekosentrik tutumları ile antroposentrik tutumları arasında düşük düzeyde pozitif yönde, antipatik tutum ları arasında negatif yönde orta düzeyde bir ilişki bulunmuştur. Antroposentrik ve antipatik tutumlar arasında da pozitif yönde düşük düzeyde anlamlı bir ilişki tespit edilmiştir. Korelasyon katsayısının .01-.29 arasında olması iki değişken arasında düşük düzeyde; .30-.70 arasında olması orta düzeyde bir ilişkinin varlığını göstermektedir (Büyüköztürk, 2011). Öğretmen adaylarının çevre odaklı (ekosentrik) tutumları yükseldikçe antipatik tutumları azalmaktadır. Amerigo vd., (2007) çevre odaklı anlayışlara sahip olmanın, ekolojik eylemleri gerçekleştirme olasılıklarının daha yüksek olduğunu belirtmiştir. Böylece ekosentrik tutumların daha yüksek olması çevreye yönelik olumlu davranışlarda da artışa yol açacaktır. Ekosentrik tutumlar ile antipatik tutumlar arasında negatif yönde bir ilişkiden kaynaklı olarak olumsuz davranışları da azaltacaktır. Çevre eğitiminde çevre dostu tutum ve davranışların kazandııımasında önemli rolü olan öğretmenlerin de aynı tutum ve davranışlara sahip olması öğrencilere model olma yönüyle katkı sağlayacaktır. Öğretmen adaylarının da aynı şekilde ekosentrik anlayışları bu tutum ve davranışlara götürecektir. Erten ve Aydoğdu'nun (2012) çalışmalarında da mevcut araştırma ile aynı doğrultuda sonuçlar ortaya çıkmıştır.

Bu sonuçlar doğrultusunda öğretmen adaylarının çevreye duyarlı, çevreyi daha çok merkeze alan anlayışlarını artıracak öğrenme ortamlarında yer alması çevre merkezli tutumlarının artmasına ve itici tutumlarının azalmasına yol açabilir. Özellikle erkek öğrencilerin bu öğrenme ortamlarında yönlendirilmesi ve aktif katıımı olumlu tutumların daha fazla geliştirilmesine katkı sağlayabilir. Öğretmen adaylarının antroposentrik tutumlarını daha fazla doğa merkezli bir anlayışa dönüştürmede çevre konu/kavramlarının yer aldığı ders içerikleri insan merkezli ve antipatik tutumlardan uzak oluşturulabilir. Bu içerikleri destekleyecek, öğretmen adaylarının da katılımının olduğu açık hava etkinlikleri yapılabilir. Aynı zamanda eğitim fakültelerinde yer alan ders içeriklerindeki çevre konu/kavramları da artırılabilir, sadece çevre odaklı dersler de seçmeli dersler olarak eklenebilir.

\section{Kaynakça}

Alpak Tunç, G. (2015). Fen Bilgisi Öğretmen Adaylarının Çevreye Yönelik Etik Yaklaşımları İle SürdürülebilirÇevreye Yönelik Tutumlarının Incelenmesi. Yayımlanmamış Yüksek lisans tezi. Adnan Menderes Üniversitesi, Fen Bilimleri Enstitüsü, Aydın.

Amérigo, M., Aragonés, J. I., Frutos, B., Sevillano, V. ve Cortés, B. (2007). Underlying Dimensions of Ecocentric and anthropocentric environmental beliefs. The Spanish Journal of Psychology, 10(1), 97-103.

Atasoy, E. ve Ertürk, H. (2008). ilköğretim Öğrencilerinin Çevresel Tutum ve Çevre Bilgisi Üzerine Bir Alan Araştırması. Erzincan Eğitim Fakültesi Dergisi, 10(1), 105-122.

Ateş, M. ve Karatepe, A. (2013). Üniversite Öğrencilerinin "Çevre" Kavramına İlişkin Algılarının Metaforlar Yardımıyla Analizi. The Journal of Academic Social Science Studies, 6(2), 1327-1348.

Atlı, K., Uzun, N., Saraç, C., Sağlam, N. ve Sağlam, S. (2015). Öğrencilerin Ekosentrik, Antroposentrik ve Çevreye Yönelik Antipatik Tutumlarının Akademik Başarıları ile iliş̧kisi. International Journal of Innovative Research in Education, 2(1), 39-47. 
Aydın, F. (2011). Üniversite Öğrencilerinin "Çevre" Kavramına Illişkin Metaforik Algıları. Doğu Coğrafya Dergisi, 26, 25-44.

Bahar, M., Bağ, H. ve Bozkurt, O. (2008). Pre-Service Science Teachers' Understandings of An Environmental Issue: Ozone Layer Depletion, Ekoloji, 18(69), 51-58.

Büyüköztürk Ş. (2011). Sosyal Bilimler lç̧in Veri Analizi El Kitabı. Ankara: Pegem Akademi.

Cardeiro, R.W. ve Sayler, R.D. (1994). Student Knowledge of Environmental and Natural Resource Issues in The Pacific Northwest. Journal of Natural Resources Life Science Education, 23(2), 132136.

Casey, P. J. ve Scott K. (2006). Environmental Concern and Behaviour in An Australian Sample Within An Ecocentric - Antropocentric Framework, Australian Journal of Psychology, 58(2), 57-67.

Demir, H. i. ve Yoldaş, C. (2016). İlköğretim Öğretmen Adaylarının Çevre Tutumlarının Farklı Değişkenler Açısından Incelenmesi. Researcher: Social Sciences Studies, 4(1), 31-51.

Eagles, P. F. J. ve Demare, R. (1999) Factors Influencing Children's Environmental Attitudes. The Journal of Environmental Education, 30(4), 33-37.

Erol, G. H. ve Gezer, K. (2006). Sınıf Öğretmenliği Öğretmen Adaylarının Çevreye ve Çevre Sorunlarına Yönelik Tutumları. International Journal of Environmental and Science Education, 1 (1), 65-77.

Erten, S. (2004). Çevre Eğitimi ve Çevre Bilinci Nedir, Çevre Eğitimi Nasıl Olmalıdır? Çevre ve Insan Dergisi, Çevre ve Orman Bakanlığı Yayın Organı, 65/66, 1-13.

Erten, S. (2007). Ekosentrik, Antroposentrik ve Çevreye Yönelik Antipatik Tutum Ölçeğinin Türkçeye Uyarlama Çalışması. Eğitim Araştırmaları Dergisi, 28, 67-74.

Erten, S. ve Aydoğdu, C. (2011). Türkiyeli ve Azerbaycanlı Öğrencilerde, Ekosentrik, Antroposentrik ve Çevreye Karşı Antipatik Tutum Anlayışları. Hacettepe Üniversitesi Eğitim Fakültesi Dergisi, 41, 158-169.

Esa, N. (2010). Environmental Knowledge, Attitude and Practice of Student Teachers. International Journal of Geographical and Environmental Education, 19(1), 39-50.

Fishman, L. (2005). The Effects of Local Learning on Environmental Awareness in Children: An Empirical Investigation. The Journal of Environmental Education, 36(3), 39-50.

Fraenkel, J. R. ve Wallen, N. E. (2009). How to Design and Evaluate Research in Education. Boston: McGraw-Hill.

Gerçek, C. (2016). Üniversite Öğrencilerinin Çevre Etiğine Yönelik Algıları. Elektronik Sosyal Bilimler Dergisi, 15(59), 1100-1107.

Karakaya, Ç. ve Çobanoğlu E. O. (2012). Insanı Merkeze Alan (Antroposentrik) ve Almayan (Nonantroposentrik) Yaklaşımlara Göre Eğitim Fakültesi Son Sınıf Öğrencilerinin Çevreye Yönelik Bakış Açıları. Türk Fen Eğitimi Dergisi, 9(3), 23-35.

Kortenkamp, K. V. ve Moore, F. C. (2001). Ecocentrism and Anthropocentrism: Moral Reasoning About Ecological Commons Dilemmas. Journal of Environmental Psychology, 21, 261-272.

Leppänen, J., M., Haahla, A. E., Lensu, A. M. ve Kuitunen, M. T. (2012). Parent-Child Similarity in Environmental Attitudes: Apairwise Comparison. The Journal of Environmental Education, 43(3), 162-176.

Mackinnon, B., ve Fiala, A. (2014). Ethics: Theory and Contemporary Issues. Nelson Education.

Michail, S., Stamou, A. G. ve Stamou, G. P. (2007). Greek Primary School Teachers' Understanding of Current Environmental Issues: An Exploration of Their Environmental Knowledge and Images of Nature. Science Education, 91(2), 244-259.

Pooley, J. A. ve O'Connor, M. (2000). Environmental Education and Attitudes: Emotions and Beliefs are What is Needed. Environment and Behavior, 32(5), 711-723. 
Özdemir, T. (2014). Fen Fakültesi Öğrencilerinin Çevreye Yönelik Bakış Açılarının (Antroposentrik, Ekosentrik, Antipatik) Faklı Değişkenler Açısından Değerlendirilmesi. Yayımlanmamış Yüksek lisans tezi. Karadeniz Teknik Üniversitesi, Eğitim Bilimleri Enstitüsü, Trabzon.

Ratinen, I. J. (2013). Primary Student-Teachers' Conceptual Understanding of The Greenhouse Effect: A Mixed Method Study. International Journal of Science Education, 35(6), 929-955.

Seçgin, F., Yalvaç, G. ve Çetin, T. (2010). İlköğretim 8. Sınıf Öğrencilerinin Karikatürler Aracılığıyla Çevre Sorunlarına İlişkin Algıları. International Conference on New Trends in Education and Their Implications, Antalya, Turkiye.

Sungur, S. A. (2017). Lisans Öğrencilerinin Çevreye Yönelik Etik Tutumları. Akademik Sosyal Araştırmalar Dergisi, 41, 469-479.

Sürmeli, H. ve Saka M. (2013). Preservice Teachers' Anthropocentric, Biosentric And Ecocentric Environmental Ethics Approaches. Internaional Journal of Academie Research, 5 (5), 159163.

Şama, E. (2003). Öğretmen Adaylarının Çevre Sorunlarına Yönelik Tutumları. Gazi Eğitim Fakültesi Dergisi, 23 (2), 99-110.

Taylor, N., Doff, T., Jenkins, K. ve Kennelly, J. (2007). Environmental Knowledge and Attitudes Among A Cohort of Pre-Service Primary School Teachers in Fiji. International Research in Geographical and Environmental Education, 16(4), 367-379.

Thompson, S. C. G. ve Barton, M. A. (1994). Ecocentric and Anthropocentric Attitudes Toward The Environment. Journal of Environmental Psychology, 14(2), 149-157.

Tuncer, G., Sungur, S., Tekkaya, C. ve Ertepınar, H. (2007). A Comparative Study on Pre-Service Teachers' and Elementary Students' Attitudes towards The Environment. International Research in Geographical and Environmental Education, 16(2), 188-198.

Uitto, A., Juuti, K., Lavonen, J., Byman, R ve Meisalo, V. (2011). Secondary School Students' Interests, Attitudes and Values Concerning School Science Related To Environmental Issues in Finland. Environmental Education Research, 17(2), 167-186.

Uzun, N. ve Sağlam, N. (2006). Orta Öğretim Öğrencileri için Çevresel Tutum Ölçeği Geliştirme ve Geçerliliği. Hacettepe Üniversitesi Eğitim Fakültesi Dergisi, 30, 240-250.

Vlaardingbroek, B. ve Taylor, T. G. N. (2007). The Environmental Knowledge and Attitudes of Prospective Teachers in Lebanon: A Comparative Study. International Research in Geographical and Environmental Education, 16(2), 120-134. 


\section{Extended Summary}

In this research, it has been aimed to determine the anthropocentric, ecocentric and antipathetic environmental attitudes of the prospective teachers who are receiving education in Primary Education, Social Studies Education and Science Education Branches, at which environment-oriented classes take place more in curriculum, in the Faculty of Education Undergraduate Program.

In line with this objective, answer to the following questions has been sought.

1) Do the prospective teachers' anthropocentric, ecocentric and antipathetic attitudes towards environment differ according to gender?

2) Do the prospective teachers' anthropocentric, ecocentric and antipathetic attitudes towards environment differ according to the academic education program studied at?

3) Do the prospective teachers' anthropocentric, ecocentric and antipathetic attitudes towards environment differ according to the class level?

4) Is there a relationship among the prospective teachers' anthropocentric, ecocentric and antipathetic attitudes towards environment?

Comparative survey method has been used in the research aiming to determine the anthropocentric, ecocentric and antipathetic environmental attitudes of the prospective teachers who are receiving education in Primary Education, Social Studies Education and Science Education Branches, to analyze these in terms of some variables and to detect the relationship among them.

The research has been carried out with the participation of 800 prospective teachers who are receiving education in Primary Education, Social Studies Education and Science Education Branches of the Faculty of Education in Kastamonu University.

Within the scope of the research, data have been gathered by means of the Ecocentric, Anthropocentric and Antipathetic Environmental Attitude Scale developed by Thompson and Barton (1994) and adapted to Turkish by Erten (2007). 27 items in total exists in the scale, as 12 items in ecocentric attitudes, 8 items in anthropocentric attitudes and 7 in antipathetic attitudes. The scale has been developed in Likert type and 7-point scale. In the study, Cronbach Alpha reliability co-efficient of ecocentric attitudes has been found as 77, Cronbach Alpha reliability co-efficient of anthropocentric attitudes as 70 and Cronbach Alpha reliability co-efficient of antipathetic attitudes as 87 .

Data gathered in the research have been analyzed with SPSS 21 Program. Within the scope of research, descriptive statistics for anthropocentric, ecocentric and antipathetic attitude points of the students participated in the study group and independent groups $t$ test to determine whether a statistically significant difference exists among these points according to gender have been carried out. One-way variance analysis (ANOVA) has been used for the class level and with regards to the academic education program studied at. Pearson Product Moment Correlation Coefficient has been calculated for the determination of the relationship among anthropocentric, ecocentric and antipathetic attitude points in the scale.

It has been found that the prospective teachers' ecocentric attitude points and anthropocentric attitude points are over the mean point, and when analyzed the other dimension, namely antipathetic attitude points, they are below the mean point.

The average of points for prospective teachers' ecocentric and antipathetic attitudes differs according to gender. In terms of ecocentric attitude points, while female students have a higher point average than male students have, the reverse situation is in question for antipathetic attitude points and at this dimension, the points for female students have been found as lower compared to the male students.

With regards to the class level variable, it has been found that the highest point in ecocentric attitude points of the prospective teachers belongs to the $4^{\text {th }}$ grades. Beside this, it is seen that the points of the $1^{\text {st }}$ and $2^{\text {nd }}$ grades are very close to each other in anthropocentric attitude points and the highest average is in the $2^{\text {nd }}$ grades. As for antipathetic attitude points, similarly the points of the $1^{\text {st }}$ and $2^{\text {nd }}$ grades are also found very close to one another and the highest point is in the $1^{\text {st }}$ class level. When these points obtained by the students are evaluated as based on the class level, a significant difference has been 
found. In terms of ecocentric attitude points, when the points obtained by the students in the level of $2^{\text {nd }}$ and $4^{\text {th }}$ class are compared, a statistically significant difference for the $4^{\text {th }}$-grade students has been detected. For antipathetic attitude points, when the points of the students in the $1^{\text {st }}$ and $4^{\text {th }}$ class; and the $2^{\text {nd }}$ and $4^{\text {th }}$ class level are compared, the result has been significant in favor of the students in the $1^{\text {st }}$ and $2^{\text {nd }}$ class level, respectively.

It has been seen that the highest point in ecocentric attitude points belongs to the Primary Education students, when the points of prospective teachers are analyzed, as for the academic program at which they are studying. Besides, it has been revealed that the students receiving Social Studies Education have the highest average in anthropocentric and antipathetic attitude points. A significant difference has been determined among antipathetic attitude points of the prospective teachers, as well as no significant difference has appeared to be in terms of the points for their ecocentric and anthropocentric attitudes, according to the education program they are studying at. When the students receiving education in Social Studies and Primary Education and Science Education students are compared according to antipathetic attitude points, a significant difference in favor of the students in Social Studies Education has been detected.

Within the scope of the study, the relationship among prospective teachers' points for ecocentric, anthropocentric and antipathetic attitudes have also been analyzed. There is a low-level positive relationship between ecocentric attitude points and anthropocentric attitude points. Similarly, a positive relationship at low level is also seen between anthropocentric attitude points and antipathetic attitude points. As for the relationship between ecocentric attitude points and antipathetic attitude points, it has been detected as negative at low level.

As the result of research, it can be stated that prospective teachers have ecocentric and anthropocentric environmental attitudes, and their antipathetic attitudes are less. It has been found out that female students have more environment-oriented attitudes as compared to the male students, when their ecocentric attitudes are analyzed according to gender. This case may be resulted from the females' conventionally social roles as to be tender-hearted, nurturing and protective (Casey and Scott, 2006). Leppanen et al. (2012) has also detected more positive and/or favorable environmental attitudes among mothers and daughters in their researches carried out on the parents and their children and pointed out that opinions about gender roles can influence attitudes. A significant difference has not appeared to be in prospective teachers' anthropocentric attitudes. When their antipathetic attitudes are evaluated, it can be said that male students have more antipathetic attitudes towards environment, compared to female students.

Considering the results for prospective teachers' ecocentric, anthropocentric and antipathetic attitudes in terms of class level, for ecocentric attitude points, as the class level increases, points for attitudes increase in the same direction, too. As for antipathetic attitudes, they decrease contrary to ecocentric attitudes and as the class level increases. This situation can be associated with the lessons taken as long as the class level goes up.

Regarding the program at which they study, a significant difference in prospective teachers' ecocentric and anthropocentric attitudes has not been detected. However, in their antipathetic attitudes, a significant difference is seen. That the students receiving Social Studies Education have more antipathetic attitude as compared with the students studying at Primary Education and Science Education has been recognized.

When considered the relationship among ecocentric, anthropocentric and antipathetic attitudes toward environment, a positive relation between ecocentric attitude and anthropocentric attitude and a negative relation between ecocentric attitude and antipathetic attitude have been established. A positively significant difference between anthropocentric and antipathetic attitudes has been also determined.

In accordance with these results, prospective teachers' taking place in environmentally-conscious and more ecocentric learning environments can lead to the increase in their ecocentric attitudes. Moreover, environmental subjects / concepts in course contents involved in the curriculum of education faculties can be enhanced, and only environment-oriented lessons can be also added as elective courses. 